\title{
Massive Pulmonary Embolism Secondary to Late Pacemaker Lead Thrombosis
}

\author{
Ambiga Kathirgamanathan ${ }^{1}$, Haider A Naqvi ${ }^{1}$, Upul Premawardhana ${ }^{1,2}$ and Krishna Kishor Kadappu ${ }^{1,2^{*}}$ \\ 1Cardiology Department, Campbelltown Hospital, Australia
}

2Western Sydney University, Australia

Submission: April 03, 2017; Published: June 05, 2017

*Corresponding author: Krishna Kishor Kadappu, Director, Cardiac Diagnostic Unit, Campbelltown Hospital, Campbelltown, NSW, 2560, Australia, Tel: +61 2 46343483; Fax: +61 2 46343481; Email: Kishor.Kadappu@sswahs.nsw.gov.au

\section{Introduction}

Pacemaker lead induced Venous thrombosis occurs in 30\% to $50 \%$ of permanent trans-venous pacemaker implantation [1]. Out of these only $0.6-3.5 \%$ cases have serious thromboembolic complications [2]. In an autopsy series, almost half of the patients were found to have thrombi in pacemaker leads [3], however, intracardiac thrombosis due to pacemaker lead causing serious embolic complication is a rare entity. We report a case of a large pacemaker lead thrombus leads to massive pulmonary embolism after 10 years of implantation.

\section{Case Report}

A 77 year old man who had a dual chamber pacemaker implanted 10 years back for sick sinus syndrome. He had regular follow up visits including device check and all were found to be in order. He presented to our institution with 2 weeks history of shortness of breath and sudden onset of right sided pleuritic chest pain. There was no history of fever or other infective symptoms. No risk factors for pulmonary embolism identified from the history. Physical examination and chest X-ray revealed no abnormalities.

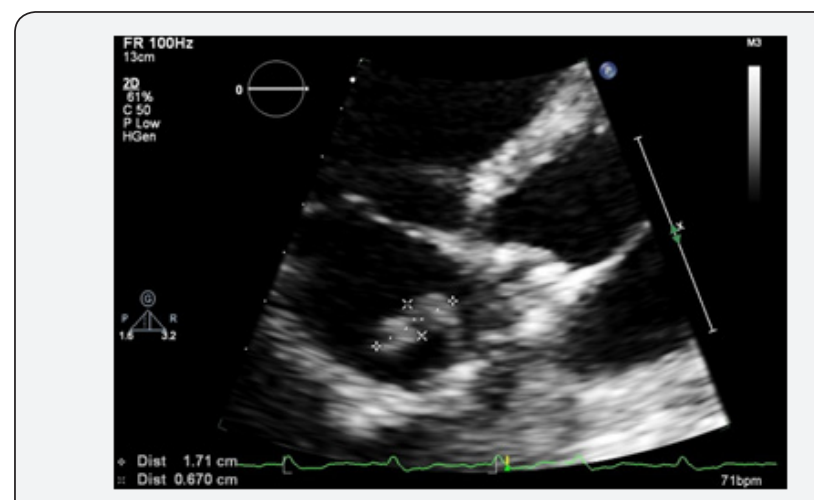

Figure 1: Parasternal short axis showing thrombus attached to pacemaker lead.

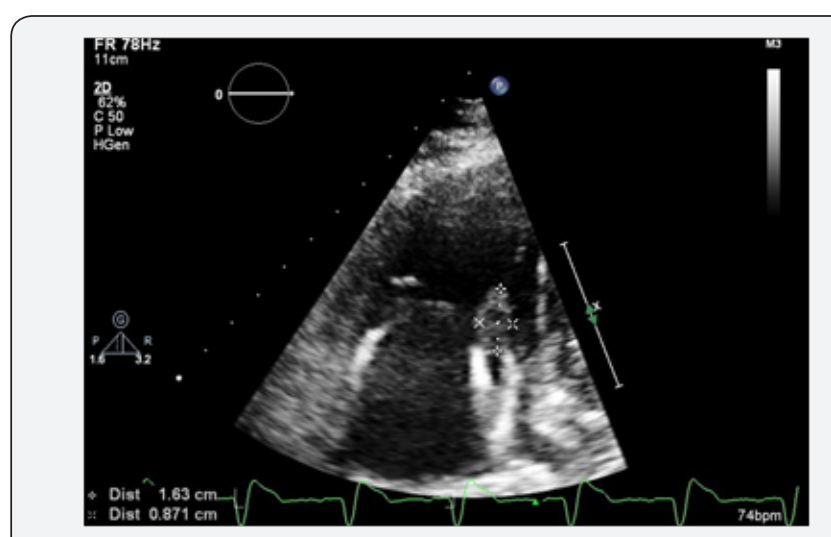

Figure 2: Apical 4 chamber view showing the thrombus.

Electrocardiography revealed a paced rhythm. All laboratory parameters were unremarkable except mild elevation of high sensitive troponin as well as elevated D-dimer. His blood gas analysis showed significant hypoxemia. He had an echocardiogram which revealed highly mobile, echo dense irregular mass attached to pacemaker lead in right atrium (Figure $1 \& 2$ ). He underwent a CT pulmonary angiogram, which demonstrated saddle pulmonary emboli (Figure 3 ).

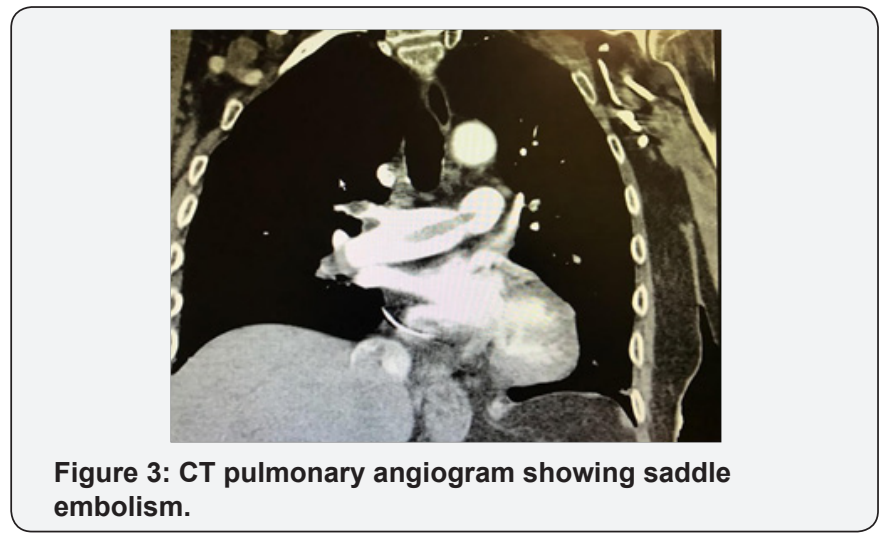


He was haemodynamically stable, therefore initially treated with intravenous unfractionated heparin infusion. The patient was stable and a febrile throughout his hospital stay. Serial blood cultures were negative. There were no clear risk factors identified as a cause for thrombosis, including negative thrombophilic and malignancy screening. Pacemaker check revealed good function with normal sensitivity and threshold.

He was commenced on Rivaroxabanfor long term following initial intravenous anticoagulation and subsequent follow-up was organized.

\section{Discussion}

Among patient with cardiac devices, the incidence of asymptomatic clot adhered to the device lead by transthoracic echocardiography is $1.4 \%$ [4]. Although thromboembolic complication in pacemaker implantation is rare, as in our patient it can lead to life threatening complication like pulmonary embolism. Presence of pulmonary embolism in a patient with pacemaker should aroused the suspicion of pacemaker lead as a source of thromboembolism and prompt investigation is warranted [5]. Even though, transoesophgeal echocardiogram is more sensitive to pick up thrombus; transthoracic echocardiogram could be used as a routine tool to detect lead thrombosis as in our case.

Established risk factors for venous thrombosis and multiple pacemaker leads increases the risk of development of thrombus in pacemaker lead. It was also established, atrial fibrillation increases the risk of clot in the cardiac devices by eight fold [4]. Hence, risk factor assessment prior to implantation of cardiac device will be useful to prevent early thrombus formation and serious adverse effects like pulmonary embolism in this set of patients [6]. However, these may not be helpful in late thrombus formation like this patient.

Our case is a unique example of a very late complication of pacemaker lead thrombosis after a decade of pacemaker implantation with leading to massive pulmonary embolism without any indefinable risk factors which is not reported in literature.

\section{References}

1. Oginosawa $\mathrm{Y}, \mathrm{Abe} \mathrm{H}$, Nakashima $\mathrm{Y}$ (2002) The incidence and risk factors for venous obstruction after implantation of transvenous pacing leads. Pacing Clin Electrophysiol 25(11): 1605-1611.

2. Barakat K, Robinson NM, Spurrell RA (2000) Transvenous pacing leadinduced thrombosis: a series of cases with a review of the literature. Cardiology 93(3): 142-148.

3. Novak M, Dvorak P, Kamaryt P, Slana B, Lipoldova J (2009) Autopsy and clinical context in deceased patients with implanted pacemakers and defibrillators: intracardiac findings near their leads and electrodes. Europace 11(11): 1510-1516.

4. Rahbar AS, Azadani PN, Thatipelli S, Fleischmann KE, Nguyen N, et al. (2013) Risk factors and prognosis for clot formation on cardiac device leads. Pacing Clin Electrophysiol 36(10): 1294-1300.

5. Coleman DB, DeBarr DM, Morales DL, Spotnitz HM (2004) Pacemaker lead thrombosis treated with atrial thrombectomy and biventricular pacemaker and defibrillator insertion. Ann Thorac Surg 78(5): e83-e84.

6. van Rooden CJ, Molhoek SG, Rosendaal FR, Schalij MJ, Meinders AE et al. (2004) Incidence and risk factors of early venous thrombosis associated with permanent pacemaker leads. J Cardiovasc Electrophysiol 15(11): 1258-1262.

\section{Your next submission with Juniper Publishers will reach you the below assets}

- Quality Editorial service

- Swift Peer Review

- Reprints availability

- E-prints Service

- Manuscript Podcast for convenient understanding

- Global attainment for your research

- Manuscript accessibility in different formats

( Pdf, E-pub, Full Text, Audio)

- Unceasing customer service

Track the below URL for one-step submission https://juniperpublishers.com/online-submission.php 